https://doi.org/10.23913/ricsh.v9i18.224

Artículos Científicos

\title{
Análisis del consumo hedonista del reguetón en mujeres millennials del estado de Jalisco, México
}

Hedonistic consumption analysis of reggaeton in millennial women from Jalisco, Mexico state

Análise do consumo hedonístico de reggaeton em mulheres milenares do estado de Jalisco, México

Luz Elena Machaen López Universidad de Guadalajara, Centro Universitario de los Altos, México luz.machaen@gmail.com https://orcid.org/0000-0003-4044-5402

Paulo Alberto Carrillo Torres

Universidad de Guadalajara, México paulo.a.carrillo@gmail.com https://orcid.org/0000-0002-1142-2976

Elisander Quiroz García Universidad de Guadalajara, México elisander.eqg@gmail.com https://orcid.org/0000-0003-3023-3908 


\section{Revista Iberoamericana \\ de las Ciencias Sociales y \\ Humanísticas}

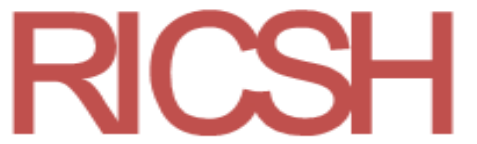

ISSN: $2395-7972$

\section{Resumen}

El género musical reguetón de origen latino, es un híbrido compuesto por diversos géneros y ritmos populares, que ha sido criticado desde sus inicios por ser precursor de la violencia, detonante de actos criminales, portador de contenido sexual explicito e implícito, misógino y promotor del perreo (baile en el que se explota sexualmente a la mujer a través de movimientos eróticos y soeces de manera semidesnuda). Además ha sido considerado artísticamente deficiente, como una representación muy elemental de expresión musical. Aun así, hoy en día ha alcanzado un éxito comercial mundial, escuchado por hombres y mujeres de todas las edades lo cual ha provocado que intérpretes de otros géneros incursionen en él con excelentes resultados. Considerando estas observaciones, en el presente estudio se planteó la siguiente interrogante: ¿cuáles son las razones que motivan a mujeres de la generación millennials (es decir, aquellas nacidas entre 1981 y 1997), a consumir por placer este tipo de música?

Para intentar ofrecer una respuesta se construyó una encuesta semiestructurada en la cual se emplearon técnicas proyectivas, así como la reproducción del audio y la lectura de letra de la canción. La selección de las mujeres se concretó mediante un muestreo en cadena o bola de nieve. En total participaron seis universitarias del estado de Jalisco (México).

Los resultados evidencian que las millennials escuchan el género debido a que les provoca activación y energía para realizar sus actividades cotidianas, así como alegría, diversión y bienestar. El género, en otras palabras, logra cambiar su estado anímico de tristeza o ansiedad por relajación y felicidad. También se encontró que no prestan demasiada atención a las letras de las canciones y que el ritmo es lo que las estimula a consumirlo, salvo en aquellas ocasiones donde las letras son altamente denigrantes o pervertidas.

Palabras clave: consumo musical, hedonismo, millennials, reguetón.

\section{Abstract}

The reggaeton, of Latin origin, is a hybrid musical genre, composed of various genres and popular rhythms, which has been criticized since its beginning as violence precursor, criminal acts detonator, explicit and implicit sexual content bearer, misogynist and promoter of perreo (dance in which women are sexually exploited through erotic and vulgar movements by semi-nude way). Moreover, it is considered artistically deficient as an elemental representation of musical expression. Even so, today it has achieved global commercial success, it is heard by men and 


\section{Revista Iberoamericana \\ de las Ciencias Sociales y \\ Humanísticas}

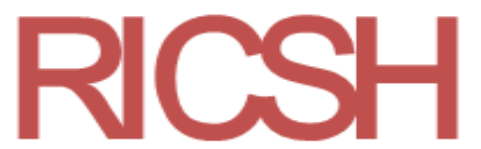

ISSN: $2395-7972$

women of all ages, which has caused that performers of other genres ventured into reggaeton with excellent results. Considering these observations, in the present study was raised the following question: what are the reasons that motivate millennial women, those women born between 1981 and 1997, to consume reggaeton for pleasure?

To try to offer an answer, a semi-structured survey was constructed in which projective techniques were used; as well as the reproduction of the audio and the reading of the song lyrics. The selection of women was made through chain or snowball sampling. In total, six university students from Jalisco state (Mexico) participated.

The results show that millennial women listen reggaeton because it provokes them activation and energy to carry out their daily activities, as well as joy, fun and well-being. In other words, the reggaeton is able to change their sadness or anxiety mood to relaxation and happiness. It was also found that they do not pay much attention to the song lyrics, and the rhythm is what stimulates them to consume reggaeton, except on those occasions where the lyrics are highly degrading or perverted.

Keywords: musical consumption, hedonism, millennials, reggaeton.

\section{Resumo}

O gênero musical reggaeton, de origem latina, é um híbrido composto por diversos gêneros e ritmos populares, que vem sendo criticado desde o seu início por ser precursor da violência, desencadeador de atos criminosos, portador de conteúdo sexual explícito e implícito, misógino e promotor de perreo (dança em que as mulheres são exploradas sexualmente através de movimentos eróticos e vulgares de forma semi-nua). Também foi considerado artisticamente deficiente, como uma representação muito elementar da expressão musical. Ainda assim, hoje alcançou sucesso comercial mundial, ouvido por homens e mulheres de todas as idades, o que fez com que intérpretes de outros gêneros entrassem com excelentes resultados. Diante dessas constatações, o presente estudo levantou o seguinte questionamento: quais os motivos que motivam as mulheres da geração milenar (ou seja, as nascidas entre 1981 e 1997) a consumir esse tipo de música por prazer?

Para tentar dar uma resposta, foi construída uma pesquisa semiestruturada na qual foram utilizadas técnicas projetivas, bem como a reprodução do áudio e a leitura da letra da música. A seleção das 


\section{Revista Iberoamericana \\ de las Ciencias Sociales y \\ Humanísticas}

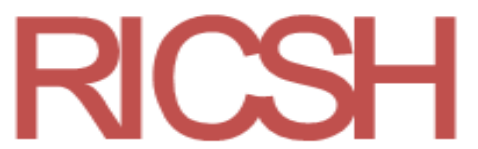

ISSN: $2395-7972$

mulheres foi feita por amostragem em cadeia ou bola de neve. No total, participaram seis estudantes universitários do estado de Jalisco (México).

Os resultados mostram que a geração do milênio escuta o gênero porque ele provoca ativação e energia para realizar suas atividades diárias, além de alegria, diversão e bem-estar. Em outras palavras, o gênero consegue mudar seu humor de tristeza ou ansiedade para relaxamento e felicidade. Verificou-se também que eles não prestam muita atenção nas letras das músicas e que o ritmo é o que os estimula a consumi-la, exceto nas ocasiões em que a letra é altamente degradante ou pervertida.

Palavras-chave: consumo de música, hedonismo, millennials, reggaeton.

Fecha Recepción: Diciembre 2019

Fecha Aceptación: Junio 2020

\section{Introducción}

El reguetón es un género de la música urbana derivado de la combinación de ritmos latinos como reggae, hip hop, rap, salsa y merengue. Tiene sus orígenes en los años 70 en Panamá, pero cobró auge en los barrios más pobres de Puerto Rico en la década de los 90, y luego llegó a Estados Unidos para exportarse al mundo entero (Bowen citado por Martínez, 2014). Actualmente, es uno de los géneros con mayor popularidad cultural y es reconocido por ser un fenómeno musical que lleva más de 20 años presente en la vida de los latinoamericanos.

Sin embargo, es ampliamente desacreditado por promover la violencia y el contenido sexual, y por ser un género musical "trasgresor del orden y violador de la moral" (Baker, 2011, citado por Imboden, 2016, p. 30). En palabras de Castro y Quishpe (2019), es promotor de obscenidad, crimen y drogadicción, "caracterizado por promover y difundir patrones de comportamiento entre la juventud que atentan contra ciertas normas morales de la sociedad mexicana actual" (Martínez, 2014, p. 64).

Además, es señalado de ser un género musical misógino en el que se margina y explota a la mujer mediante sus letras con alto contenido sexual, que la reduce a un objeto carnal que complace los deseos del reguetonero y hace alusión a su comportamiento concupiscente, salvaje y amoral. Según Martínez (2014), en este género musical se hace referencia explícita a la figura física de la mujer y al deseo irreverente del acto sexual, el cual se destaca en su manera sensual de perrear (mover la pelvis y el resto del cuerpo de manera escandalosamente sensual al son del ritmo, imitando el coito), como lo demuestran los ejemplos de algunas de sus letras: "Dame un chupi 


\section{Revista Iberoamericana \\ de las Ciencias Sociales y \\ Humanísticas}

ISSN: $2395-7972$

chupi, que yo lo disfruti, abre la bocuti, y trágatelo tuti... dale al ritmo bechi, lléname de bechi, sácate la lengua que te voy a dar la lechi”" (García, 2012). "Ella quiere hmm haa hmm, voy a darle hmm haa hmm, para que sienta hmm haa hmm y de nuevo hmm haa hmm, vamo mamita muévelo como tu quiera, que no me importa si te vuelve una fiera... sé que te gustó el beso en el cuello, ahora voy por tu pantalón, pa' poné mi sello” (Leka el Poeta, 2016). Para el reconocido poeta Edwin Reyes, esta constituye "una forma primitiva de expresión musical, que transmite las formas más elementales de la emoción a través de un sonsonete embrutecedor y agresivo" (citado por Negrón y Rivera, 2009, párr. 5).

En este contexto, la presente investigación procura demostrar - a través de un estudio cualitativo - las razones y motivos por los cuales las mujeres millennials consumen por voluntad y satisfacción propia el reguetón; para ello, se parte del consumo hedonista para comprender lo que propicia que este tipo de música esté presente en el mercado femenino, a pesar de los señalamientos citados anteriormente. Cabe mencionar que los millennials (nuestra población objeto de estudio) representan las nuevas generaciones de consumidores, es decir, adultos jóvenes nacidos entre 1981 y 1997 (Ricaurte y Ortega, 2013, citados por Cataldi y Dominighini, 2015).

\section{Hedonismo}

El hedonismo — según Tafur (2016) — es un término que acuñó por primera vez el filósofo griego Epicuro, quien lo conceptualizó como la búsqueda del placer y la evasión del dolor. Según este pensador, las personas determinan el placer como algo bueno, de ahí que lo conciban como el principio y fin del vivir feliz. Para este filósofo, el placer no solo se satisface a través de las necesidades inmediatas como el sexo y la comida, sino también mediante la apreciación de las necesidades artísticas y del intelecto, ya que estos ofrecen más elementos para ser feliz.

Por su parte, el filósofo alemán Herbert Marcuse menciona que el hedonismo busca el placer por encima de la felicidad, atribuyendo a este aspecto la libertad por las exigencias materiales (citado por Benente, 2008). Para este autor el hedonismo es la búsqueda del placer como un aumento de la libertad individual, pero también una expresión social de experiencias y satisfacciones que invitan a la disminución de tensiones.

Por otro lado, Victor Vroom sostiene que la necesidad de actuar de cierta manera depende de la intensidad de la expectativa de que dicha acción vaya seguida de una consecuencia y del valor atractivo que esa consecuencia tenga para el individuo (Kinicki y Kreitner, 2003). 


\section{Revista Iberoamericana \\ de las Ciencias Sociales y \\ Humanísticas}

ISSN: $2395-7972$

\section{Consumo hedonista}

Para Solomon (2017) el consumo hedonista se refiere a "los aspectos multisensoriales, emocionales y fantasiosos que prevalecen en las interacciones de los consumidores con los productos" (p. 76). Esto quiere decir que el hedonismo, en el comportamiento del consumidor, se manifiesta en la forma como el individuo busca satisfacción por medio de un producto a través de sensaciones placenteras.

Al respecto, Muñoz (2004) menciona que la relación entre consumo y hedonismo se estableció a raíz de diversas investigaciones motivacionales, donde se percibían distintas interacciones con los productos de acuerdo al estilo de vida del consumidor. De esto parte la premisa de que las personas compran productos por su significado, y no solo por lo que pueden hacer con ellos. Cabe mencionar que la motivación consiste en un proceso psicológico que produce excitación, dirección y persistencia para llevar a cabo acciones voluntarias con el fin de cumplir una meta (Mitchell, 1982).

En el campo del marketing, la investigación motivacional propuesta por Dichter (citado por Hirschman y Holbrook, 1982) trata de comprender el consumo hedónico, ya que este tipo de estudios se centra en los aspectos emocionales de los productos y en las fantasías que pueden suscitar y/o cumplir en relación con las expectativas del consumidor. Es por esto que la investigación sobre el consumo hedonista del reguetón está realizada según las motivaciones que llevan a las mujeres millennials a hacer de este género musical uno de sus preferidos para su propia satisfacción.

\section{Objetivos}

\section{General}

Identificar las motivaciones que llevan a las mujeres millennials al consumo hedonista del reguetón.

\section{Específicos}

- Analizar el valor otorgado que le dan las mujeres millennials al reguetón.

- Identificar las actividades que realizan las mujeres millennials cuando escuchan reguetón.

- Identificar el estado de ánimo de las mujeres millennials al escuchar reguetón. 


\section{Revista Iberoamericana \\ de las Ciencias Sociales y \\ Humanísticas}

ISSN: 2395 - 7972

- Examinar las actitudes que muestran las mujeres millennials al escuchar canciones de reguetón.

\section{Materiales y método}

\section{Tipo de investigación}

Se empleó la investigación cualitativa, la cual "utiliza la recolección y análisis de los datos para afinar las preguntas de investigación o revelar nuevas interrogantes en el proceso de interpretación" (Hernández Sampieri, 2014, p.7). Este tipo de investigación tiene como objetivos obtener una comprensión de las motivaciones y deseos profundos de los individuos, así como la búsqueda del significado de las circunstancias que rodean a la persona y la forma como estas son representadas. De acuerdo con Hernández Sampieri (2014), con la investigación cualitativa se procura recabar las perspectivas y puntos de vista de los sujetos de estudio tales como sus emociones y experiencias.

La interpretación resultante se concentra en las sensaciones y experiencias vividas de los participantes, lo que en consecuencia se deriva en descripciones detalladas de situaciones, eventos, personas, interacciones y conductas.

El enfoque metodológico que se siguió permite recoger las opiniones basadas en las sensaciones de los sujetos de estudio, así como las actitudes que tomaron al momento de escuchar la música, incluso el bienestar generado después de relacionar el reguetón con ciertas actividades que realizan.

Se trabajó con un estudio exploratorio, el cual está determinado por el análisis del fenómeno en sí. El objetivo fue identificar y comprender los motivos por los cuales mujeres de la generación millenials disfrutan del reguetón, a pesar de ser un género criticado por muchos, ya que promueve la pérdida de valores, transgrede los códigos sociales y "convierte a la mujer en un instrumento sexual" (Urdaneta, 2007, citado por Penagos, 2012, p. 295).

El diseño de la investigación se enfoca en distinguir las cosas desde el punto de vista de los otros, describiendo, comprendiendo e interpretando lo que les produce escuchar música a través de sus experiencias mediante cualidades subjetivas (Monje Álvarez, 2011).

Se determinó acotar el estudio a mujeres de la generación millennials (también conocida como generación Y), ya que representan la nueva población de consumidores (Howe y Strauss, 2009, citados por Peñalosa y López, 2016), es decir, adultos jóvenes nacidos entre 1981 y 1997. 


\section{Revista Iberoamericana \\ de las Ciencias Sociales y \\ Humanísticas}

ISSN: $2395-7972$

Esta es identificada como la población juvenil del presente, que "se sitúan por encima de la media en áreas como la participación en la fuerza laboral y el nivel educativo" (Augustine y Nash-Stacey, 2016, párr. 3).

La selección de las participantes se hizo mediante un muestreo en cadena o bola de nieve, ya que resultó complejo encontrar personas que escucharan el género en sus actividades diarias, y no solo para bailar en fiestas, antros, bares, eventos sociales o cualquier lugar donde no se tenga control por elegir el tipo de música.

\section{Instrumento}

El instrumento que se construyó fue una entrevista semiestructurada (anexo 1), con la finalidad de generar una conversación entre el entrevistado y el entrevistador.

\section{Estructura general del instrumento}

1. Presentación.

2. Descripción de la metodología.

3. Serie de preguntas sobre el valor otorgado a la música.

4. Apartado de asociaciones sobre la satisfacción personal.

5. Presentación de canciones y letras para su audición y lectura: identidad emocional

6. Cierre de la entrevista

\section{Técnicas proyectivas}

Este tipo de técnicas permite detectar aquellas emociones y sentimientos que el consumidor difícilmente podrá expresar con palabras. Para este caso en particular se utilizaron diversos tipos de técnicas:

1. Asociación de palabras para describir el significado del reguetón.

2. Asociación de palabras para describir sus estados de ánimo al escuchar reguetón.

3. Visualización de sí misma sobre las actividades que realiza al escuchar reguetón.

4. Visualización de sus actitudes al escuchar este tipo de música y leer la letra de una canción. Para la selección de canciones se hizo primeramente una clasificación con base en tres parámetros: el primero corresponde a la antigüedad de la canción para saber si aún perdura en la mente del consumidor; el segundo se hizo con base en la tendencia que marcó la canción durante 


\section{Revista Iberoamericana \\ de las Ciencias Sociales y \\ Humanísticas}

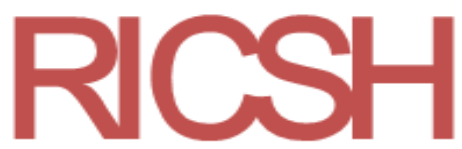

ISSN: $2395-7972$

un período de tiempo, y el tercer parámetro corresponde a la popularidad que tiene la canción actualmente.

De acuerdo con esa clasificación, la elección final de las canciones se realizó basada en dos pautas principales: 1) la posición de la canción en el Hot latin songs de Billboard y 2) que la canción tuviera al menos una pequeña participación femenina.

La intención de incluir canciones con intérpretes femeninas fue realzar un poco el involucramiento de las mujeres en el reguetón, ya que en la mayoría de canciones de este género musical son interpretadas por varones; de este modo se podrá determinar si este es un factor que influye en la selección de este tipo de música.

\section{Procedimiento}

Como se mencionó, el muestreo se realizó mediante un proceso de bola de nieve; a través de personas conocidas se realizó un seguimiento para que designaran a otras personas con gustos similares en música. Este tipo de muestreo logró conducir la investigación a seis mujeres millennials radicadas en distintos puntos del estado de Jalisco.

Se programó una cita con cada una de las personas para realizar la entrevista a profundidad. La duración de cada encuentro fue aproximadamente de 30 minutos; en estas se utilizó el instrumento semiestructurado construido y se utilizaron las técnicas proyectivas descritas para tener un acercamiento a sus reacciones al hacer las asociaciones y asimismo analizar sus reacciones cuando en condiciones "normales" escuchan este tipo de música. De igual forma, se empleó la canción escrita para determinar si las letras de este tipo de música influyen en su elección de consumo.

\section{Resultados}

Los datos se analizaron mediante la relación de palabras y sensaciones que mostraron las entrevistadas durante la sesión de preguntas. De esta relación se hizo un análisis correspondiente a los factores que influyen a las mujeres millennials para que consuman reguetón de tal manera que les genere un estado de satisfacción. En la tabla 1 se muestran todos los hallazgos recabados con la finalidad de proporcionar un panorama general. 


\section{Revista Iberoamericana \\ de las Ciencias Sociales y \\ Humanísticas}

Tabla 1. Resultados encontrados

\begin{tabular}{|c|c|}
\hline Aspectos & Resultados y respuestas obtenidas \\
\hline $\begin{array}{l}\text { Aproximación y significado } \\
\text { del reguetón. }\end{array}$ & $\begin{array}{l}\text { Ritmo y baile. } \\
\text { Música para compartir y socializar. } \\
\text { Activación para realizar actividades. } \\
\text { Alegría. }\end{array}$ \\
\hline $\begin{array}{l}\text { Estado anímico que tienen al } \\
\text { escuchar reguetón. }\end{array}$ & $\begin{array}{l}\text { Estado de energía y felicidad. } \\
\text { Impulso y motivación para realizar sus actividades cotidianas. }\end{array}$ \\
\hline $\begin{array}{l}\text { Momentos en los que } \\
\text { escuchan reguetón. }\end{array}$ & $\begin{array}{l}\text { Momentos de alegría, pues quieren escuchar música igualmente } \\
\text { alegre, que les permita prolongar el momento. } \\
\text { En momentos de tristeza o molestia, para cambiar su estado } \\
\text { anímico por alegría y relajación. }\end{array}$ \\
\hline $\begin{array}{l}\text { Actividades que realizan o } \\
\text { gustan realizar al escuchar } \\
\text { reguetón. }\end{array}$ & $\begin{array}{l}\text { Actividades del hogar, limpieza de la casa, trabajo en oficina y } \\
\text { gimnasio. }\end{array}$ \\
\hline $\begin{array}{l}\text { Actitud al escuchar el } \\
\text { reguetón. }\end{array}$ & $\begin{array}{l}\text { Sonrisa espontánea, alegría reflejada en el rostro. } \\
\text { Apertura inmediata al movimiento corporal. }\end{array}$ \\
\hline Preferencias musicales & $\begin{array}{l}\text { La letra no es importante, el ritmo prevalece. } \\
\text { Canciones de moda, con no más de dos años en el mercado. } \\
\text { Primacía de canciones acompañadas de videos con coreografía, } \\
\text { para replicar. } \\
\text { Ritmos nuevos, canciones novedosas. } \\
\text { Letras no repetitivas y canciones cortas. }\end{array}$ \\
\hline
\end{tabular}

Fuente: Elaboración propia

El desarrollo de los resultados se muestra a continuación:

\section{Valor otorgado a la música}

La primera parte de la entrevista estuvo destinada a que los sujetos de estudio relacionaran el reguetón con las actividades que suelen hacer cuando escuchan este género musical, así como las actividades que les gustaría estar realizando y aquellas acciones que están involucradas cuando se escucha este tipo de música, ya sea que las realicen o no. Mediante esta asociación se buscó que dieran una aproximación al significado que para ellas tiene el reguetón; esto permitió detectar qué es lo que buscan y sienten al escuchar esta música. 


\section{Revista Iberoamericana \\ de las Ciencias Sociales y \\ Humanísticas}

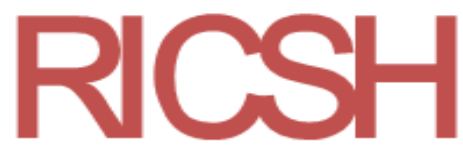

ISSN: $2395-7972$

En primer lugar, las personas entrevistadas asociaron el reguetón con ritmo y baile principalmente, aunque también se vinculó con la parte social de la persona, ya que manifestaron que es un tipo de música que suelen compartir. A pesar de esto, estas personas no suelen escuchar reguetón para bailarlo, aunque el género les remita a eso; en cambio, es un tipo de música que las activa para hacer frente a sus tareas diarias, ya sea en el hogar o en el trabajo.

En segundo lugar, las jóvenes al asociar el reguetón con baile y este con un estado de ánimo de alegría, se evidencia que es un tipo de música que escuchan para pasar el tiempo, ya que lo que las impulsa a oírlo es la sensación de alegría que les provoca el ritmo. Expresaron que en los videos musicales de reguetón aparecen personas que están en un estado de relajación y fiesta. Las entrevistadas proyectan y manifiestan sentir ese estado de energía y felicidad al escuchar la composición musical, lo que las mueve a seguir con sus tareas cotidianas. Las actividades que suelen realizar las entrevistadas van desde tareas cotidianas como limpiar la casa, ir al gimnasio e incluso trabajar.

\section{Satisfacción personal}

La segunda parte de la entrevista estuvo centrada en que los sujetos de estudio pudieran asociar lo que les hace sentir la música, así como el significado que le dan a ese género musical en sus vidas. En primer lugar, las personas entrevistadas admitieron que escuchan este género cuando están contentas, ya que no buscan arruinar ese placentero estado de ánimo.

Por otro lado, si se encuentran tristes o molestas, buscan escuchar este género para ponerse de buen humor. Manifiestan también que las letras de las canciones no son profundas, por lo tanto no requieren poner atención en el mensaje de la canción, a menos que esta sea muy ofensiva, aunque el contenido sexual de algunas letras no les molesta, de ahí que no les impida seguir disfrutando del ritmo.

\section{Identidad emocional del individuo}

Se usaron canciones para que las entrevistadas dieran respuestas más concretas y para corroborar la relación con su actitud al escuchar la música según las asociaciones que hicieron con anterioridad. Esta dinámica provocó que incluso propusieran canciones para escuchar en ese momento, lo que sirvió para que especificaran qué tipo de ritmos y cantantes asociaban más con su estado de bienestar, placer y felicidad. 


\section{Revista Iberoamericana \\ de las Ciencias Sociales y \\ Humanísticas}

ISSN: $2395-7972$

\section{Canción Mayores (Becky G., 2017)}

A pesar de que la letra les resultaba un poco molesta por tener doble sentido, les agradaba el ritmo "pegajoso". La toleraban, pero no era de su total agrado, ya que prefieren canciones "no tan pervertidas". Otra situación manifestada sobre esta canción es que ya está "muy pasada de moda", es decir, tiene más de dos años en el mercado, lo cual les genera fastidio. Las entrevistadas prefieren escuchar canciones de moda, con poco tiempo en el mercado.

\section{Canción Con altura (Rosalía, 2019)}

Esta canción fue la que mayor aceptación generó, ya que la letra y el ritmo les resultaban muy "contagiosos"; algunas incluso manifestaron saberse la coreografía del video musical, lo que les parecía más atractivo y divertido. Sin embargo, la canción tiene el aspecto negativo de ser muy repetitiva, y “escucharse en todos lados"; aun así, generaba gran aceptación por los tantos "memes” en redes sociales.

\section{Canción China (Anuel AA, Daddy Yankee, Ozuna, Karol G, J Balvin, 2019)}

La última canción generó ambivalencia, ya que les gustaba, pero utiliza ritmos que ya han sido usados en otras canciones. La letra, por otro lado, les parecía divertida, pero no le daban tanta importancia. Además, la canción les resultaba un tanto larga, sin mucho que ofrecer. La escuchan, pero no la suelen repetir, pues prefieren ritmos nuevos y canciones más cortas.

\section{Canción escrita Sin pijama (Becky G, Natti Natasha, 2019)}

La intención de este ejercicio fue corroborar si realmente las entrevistadas prestan atención a la letra de las canciones, además de detectar cuáles elementos influyen para que puedan o no reconocer una canción con solo leerla. Las entrevistadas lograron identificar de qué canción se trataba e incluso la cantaban, ya que conseguían recordar el ritmo y la melodía al leerla. Aun sin escucharla, les produjo exactamente lo mismo: las activó y generó en ellas buen humor; lo que les provoca ese estado anímico es el ritmo de la canción y el poder moverse al oír esta música. La letra realmente no es importante, a menos que sea "muy ofensiva". 


\section{Revista Iberoamericana \\ de las Ciencias Sociales y \\ Humanísticas}

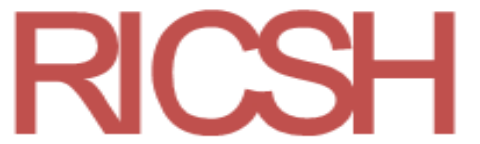

ISSN: $2395-7972$

\section{Discusión}

Los resultados evidencian que las millennials entrevistadas asocian el reguetón con ritmo, baile y, principalmente, “activación”. El reguetón es un ritmo que no suelen escuchar precisamente para bailar, sino para "activarse"; representa para ellas un baile que las invita a realizar sus actividades diarias de manera alegre, desechando la "monotonía" que sus actividades representan.

Asimismo, las invita a entrar o permanecer en un estado de alegría, bienestar y relajación, y eso es justamente la razón por la cual lo escuchan y por lo que se sienten motivadas a realizar o continuar sus actividades diarias pese a lo aburridas o fatigosas que puedan ser e independientemente del estado de ánimo en el que se encuentren antes de escuchar reguetón.

Por otro lado, la falta de profundidad de las letras de las canciones — que es una de las críticas al reguetón - no constituye un problema, sino todo lo contrario, ya que al ser canciones tan simples que solo se componen de un par de estrofas, son sumamente digeribles y contagiosas, lo cual le da un plus al reguetón.

Todas las canciones tienen una vigencia, por lo que no les agrada escuchar aquellas que tienen mucho tiempo en el mercado; aunque al principio les puede "encantar" una canción, pasado el tiempo pierden el interés, aun cuando siga cumpliendo su objetivo de llevarlas a un estado de alegría.

El reguetón genera aún más aceptación cuando el video de la canción en particular va acompañado de una coreografía, ya que a las millennials les gusta replicarla, con lo cual les resulta más atractiva y divertida.

Asimismo, prefieren escuchar canciones con ritmos nuevos, ya que los ritmos reciclados o repetitivos les desagradan, así como las canciones largas. Por eso, prefieren canciones cortas y novedosas tanto en sus letras como en sus ritmos, lo que las lleva a mayor estado de alegría.

De igual manera, no les molesta escuchar ni cantar canciones en las que se "acepta" ser una mujer fácil, con habilidades sexuales, que realiza "travesuras", entre otros aspectos que se mencionan en las letras. De hecho, parecen disfrutar las letras, deleitarse y divertirse al repetir lo que en ellas se expresa, esto a menos que la letra sea "muy denigrante u ofensiva". En este punto, habría que analizar qué representa "denigrante" y "ofensiva" para una y otra mujer.

También se hizo evidente que escuchar el ritmo les provoca inmediatamente movimiento corporal, aun estando sentadas, y en todas ellas de forma espontánea se reflejó una sonrisa, lo cual concuerda con la alegría que ellas expresan sentir de forma verbal. 


\section{Revista Iberoamericana \\ de las Ciencias Sociales y \\ Humanísticas}

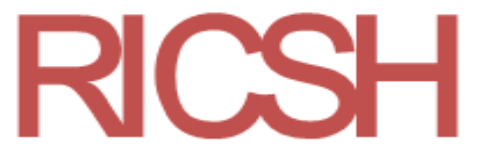

ISSN: $2395-7972$

\section{Conclusiones}

Escuchar reguetón parte de una necesidad hedonista. Este género musical lleva a las mujeres millennials entrevistadas a un estado de alegría y felicidad, lo cual permite concluir que desean satisfacer una necesidad que incluye respuestas emocionales. Querer entrar o permanecer en un estado anímico positivo es lo que impulsa la conducta de las entrevistadas a escuchar reguetón.

Se concluye también que las entrevistadas tienen altas expectativas antes de escuchar reguetón, pues ellas lo eligen por sobre otro género porque esperan que esa elección tenga consecuencias emocionales positivas en ellas. Las mujeres millennials son conscientes de la violencia, perversión, doble sentido, misoginia y contenido sexual de las canciones del reguetón que escuchan; sin embargo, el ritmo y la alegría que les genera tiene preponderancia en su elección, aunque prefieren canciones "poco ofensivas".

Como se mencionó al inicio de la investigación, la motivación es un proceso psicológico que produce excitación, dirección y persistencia para llevar a cabo acciones voluntarias con el fin de cumplir una meta; de acuerdo con la investigación y los datos recabados, se concluye que este género es una herramienta motivacional para que las mujeres millennials lleven a cabo sus actividades diarias, pues el reguetón les genera un estado anímico de alegría y felicidad.

Finalmente, se concluye que el reguetón tiene algunas ventajas ante otros géneros musicales, como lo son la simpleza y superficialidad de sus canciones - lo cual exige poca atención—, así como el ritmo y el estado anímico que genera al escucharlo.

\section{Futuras líneas de investigación}

Toda investigación realizada, contribuye a dar respuesta a las preguntas planteadas, pero de forma simultánea genera nuevas incógnitas, nuevas ideas y abre camino a nuevas líneas de investigación para complementar el trabajo ya realizado.

En este sentido, la metodología desarrollada en el presente estudio podría replicarse en mujeres de otras generaciones, en mujeres de otros estados, de otros países, incluso en mujeres de distintos estratos sociales. Podría replicarse también en hombres con distintas características sociales y culturales; todo esto con la finalidad de contrastar los resultados.

Por otro lado, también sería valioso analizar el reguetón desde una perspectiva terapéutica, para lo cual se podría crear una red de investigación con psicólogos, terapeutas y/o psiquíatras. 


\section{Revista Iberoamericana \\ de las Ciencias Sociales y \\ Humanísticas}

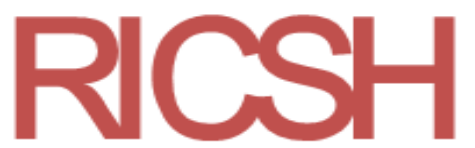

ISSN: $2395-7972$

Y finalmente valdría la pena analizar otros géneros musicales, sería importante estudiar las emociones que cada uno de los distintos géneros musicales provocan en quienes los consumen a placer y las distintas razones para consumirlos.

\section{Referencias}

Augustine, A. y Nash-Stacey, B. (2016). El índice de oportunidades generacionales: la situación de los millennials. Observatorio Económico EEUU. Recuperado de https://www.bbvaresearch.com/wpcontent/uploads/2016/08/160811_US_MillennialsOpportunityIndex_esp.pdf

Benente, M. (2008). Cultura y sociedad. Herbert Marcuse. Lecciones y Ensayos (85), 171-187. Recuperado de http://www.derecho.uba.ar/publicaciones/lye/revistas/85/09-comentariomauro-benente.pdf

Billboard (2017-2019). Hot Latin Songs Chart. Recuperado de https://www.billboard.com/

Castro, J. y Quishpe, J. (2019). Influencia de la música actual en la ética de la sociedad. Revista Caribeña de Ciencias Sociales. Recuperado de https://www.eumed.net/rev/caribe/2019/11/musica-actualsociedad.html//hdl.handle.net/20.500.11763/caribe1911musica-actual-sociedad

Cataldi, Z. y Dominighini, C. (2015). La generación millennial y la educación superior. Los retos de un nuevo paradigma. Revista de Informática Educativa y Medios Audiovisuales. 12(19), 14-21. Recuperado de http://laboratorios.fi.uba.ar/lie/Revista/Articulos/121219/A3.pdf García, O. (2012). El chupi chupi [canción]. En La fábrica de éxitos [CD]. Around the music. Hernández Sampieri, R. (2014). Metodología de la investigación. Ciudad de México, México: McGraw Hill Education.

Hirschman, E. y Holbrook, M. (1982). Hedonic Consumption: Emerging Concepts, Methods and Propositions. Journal of Marketing, 46(3), 92-101. Doi: https://doi.org/10.1177/002224298204600314

Imboden, R. (2016). Ideología y variación estilística en el reggaetón. Boletín Hispánico Helvético, 28, 29-62. Recuperado de https://www.researchgate.net/publication/315705817_Ideologia_y_variacion_estilistica_e n_el_reggaeton_C 


\section{Revista Iberoamericana \\ de las Ciencias Sociales y \\ Humanísticas}

ISSN: $2395-7972$

Kinicki, A. y Kreitner, R. (2003). Teoría de las expectativas de la motivación. En Kinicki, A. y Kreitner, R., Comportamiento organizacional: conceptos, problemas y prácticas (pp. 174179). Ciudad de México, México: McGrawHill. McGrawHill.

Martínez, D. (2014). Música, imagen y sexualidad: el reggaetón y las asimetrías de género. El Cotidiano, (186), 63-67 Recuperado

de https://www.redalyc.org/comocitar.oa?id=32531428010

Mitchell, T. (1982). Motivation: New Directions for Theory,Research, and Practice. The Academy of Management Review, 7(1), 80-88. Doi:10.2307/257251

Monje Álvarez, C. (2011). Metodología de la Investigación cuantitativa y cualitativa. Neiva (Colombia): Universidad Surcolombiana. Recuperado de https://www.uv.mx/rmipe/files/2017/02/Guia-didactica-metodologia-de-lainvestigacion.pdf

Muñoz, Y. (2004). La satisfacción del consumidor en las experiencias hedonistas. Revista Latinoamericana de Administración (33), 52-67. Recuperado de https://www.researchgate.net/publication/26471462_La_satisfaccion_del_consumidor_en _las_experiencias_hedonistas

Negrón, F. y Rivera, R. (2009). Nación reggaetón. Nueva Sociedad, 223, 29-38 Recuperado de https://nuso.org/articulo/nacion-reggaeton/

Leka el Poeta (2016). Ella quiere hmm haa hmm [canción]. La Kalle studio.

Penagos, Y. (2012). Lenguajes del poder. La música reggaetón y su influencia en el estilo de vida de los estudiantes. Plumilla Educativa, 10(2), 390-305.

Peñalosa, M. y López D. (2016) La generación de los millennials frente al consumo socialmente responsable. Cuadernos Latinoamericanos de Administración, 12(23) 73-81. Recuperado de https://www.redalyc.org/articulo.oa?id=409650120008

Solomon, M. R. (2017). Comportamiento del consumidor. Ciudad de México, México: Pearson.

Tafur, J. (2016). Hedonismo y normatividad: discusión entre Freud y Marcuse. Disertaciones, 5(2), 63-73. Recuperado de https://dialnet.unirioja.es/servlet/articulo?codigo=5891590 
Revista Iberoamericana

de las Ciencias Sociales y

Humanísticas

\begin{tabular}{|l|l|}
\hline Rol de Contribución & Autor (es) \\
\hline Conceptualización & Paulo Alberto Carrillo Torres \\
\hline Metodología & Paulo Alberto Carrillo Torres \\
\hline Software & Paulo Alberto Carrillo Torres \\
\hline Validación & Elisander Quíroz García. \\
\hline Análisis Formal & Elisander Quíroz García. \\
\hline Investigación & Elisander Quíroz García. \\
\hline Recursos & Luz Elena Machaen López \\
\hline Curación de datos & Elisander Quíroz García. \\
\hline $\begin{array}{l}\text { Escritura - Preparación del } \\
\text { borrador original }\end{array}$ & Elisander Quíroz García. \\
\hline $\begin{array}{l}\text { Escritura - Revisión y } \\
\text { edición }\end{array}$ & Luz Elena Machaen López \\
\hline Visualización & Luz Elena Machaen López \\
\hline Supervisión & Luz Elena Machaen López \\
\hline $\begin{array}{l}\text { Pdministración de } \\
\text { Adquisición de fondos }\end{array}$ & Puz Elena Machaen López \\
\hline
\end{tabular}




\section{Anexos}

Anexo 1.

\section{Entrevista semiestructurada}

\section{Presentación (tres minutos)}

$\checkmark$ Presentación

$\checkmark$ Confidencialidad

$\checkmark$ Descripción de la metodología

\section{Valor otorgado a la música (cinco minutos)}

$\checkmark$ En una palabra, ¿qué es lo primero que se te viene a la mente al escuchar la palabra "reguetón"?

$\checkmark \quad$ ¿A qué te remite ese concepto? En otras palabras, ¿qué otras actividades relacionas con esa palabra?

$\checkmark$ Entonces, ¿podrías decir que el "reguetón" es...?

\section{Satisfacción personal (siete minutos)}

$\checkmark$ En una palabra, ¿qué significa para ti escuchar este tipo de música?

$\checkmark \quad$ ¿En qué estado de ánimo te sueles encontrar cuando escuchas "reguetón?

$\checkmark$ ¿Qué actividades haces cuándo escuchas “reguetón?, ¿pones primero la música para hacer la actividad o empiezas a hacer la actividad para posteriormente poner la música?

$\checkmark$ Mientras estás haciendo esa actividad, ¿el escuchar esta música te provoca hacer otra cosa o seguir con lo que estabas?

\section{Identidad emocional del individuo (10 minutos)}

Vas a escuchar algunas canciones, siéntete en la libertad de reaccionar a lo que te provoque la canción. Posteriormente, me dirás qué sentiste al oírlas.

Canción uno: "Mayores” - Becky G ft. Bad Bunny (2017)

Canción dos: "Con Altura” - Rosalía ft. J Balvin y El Guincho (2019)

Canción tres: "China" - Anuel AA ft. Daddy Yankee, Karol G, J Balvin y Ozuna (2019)

Te voy a dar una canción para que la leas en voz alta y me des tus impresiones sobre la letra.

Canción escrita: "Sin Pijama" - Becky G y Natti Natasha (2018)

$\checkmark$ ¿Sabes de cuál canción se trata?

$\checkmark$ ¿Le habías puesto atención a letra cuando escuchabas la canción?

$\checkmark$ ¿Qué es lo más importante para ti al escuchar esta clase de música? 
Revista Iberoamericana

de las Ciencias Sociales y

Humanísticas

$\checkmark \quad$ ¿Algo más que quieras añadir?

Cierre (un minuto)

\section{Anexo 2}

Tabla 2. Listado de canciones usadas en las entrevistas y sus características

\begin{tabular}{|l|l|l|l|l|l|}
\hline \multicolumn{1}{|c|}{ Canción } & \multicolumn{1}{|c|}{ Interpretes } & Año & Parámetro & \multicolumn{1}{c|}{$\begin{array}{c}\text { Hot Latin } \\
\text { Songs }\end{array}$} & $\begin{array}{c}\text { Uso en la } \\
\text { entrevista }\end{array}$ \\
\hline Mayores & $\begin{array}{l}\text { Becky G ft. Bad } \\
\text { Bunny }\end{array}$ & 2017 & Antigüedad & $3 .^{\text {er }}$ lugar & Canción uno \\
\hline Con altura & $\begin{array}{l}\text { Rosalía ft. J Balvin } \\
\text { y El Guincho }\end{array}$ & 2019 & Tendencia & $12 .^{\circ}$ lugar & Canción dos \\
\hline China & $\begin{array}{l}\text { Anuel AA ft. } \\
\text { Daddy Yankee, } \\
\text { Karol G, J Balvin y } \\
\text { Ozuna }\end{array}$ & 2019 & Popularidad & $1 .^{\text {er lugar }}$ & Canción tres \\
\hline Sin pijama & $\begin{array}{l}\text { Becky G Natti } \\
\text { Natasha }\end{array}$ & 2018 & Antigüedad & $10 .^{\circ}$ lugar & Canción escrita \\
\hline
\end{tabular}

Fuente: Elaboración propia, basado en Hot Latin Songs chart (2017-2019). 